\title{
Effectiveness of workstation design on reducing musculoskeletal risk factors and symptoms among semiconductor fabrication room workers
}

\author{
Ro-Ting Lin, Chang-Chuan Chan*,1 \\ Institute of Occupational Medicine and Industrial Hygiene, College of Public Health, National Taiwan University, Taiwan
}

Received 23 June 2005; received in revised form 4 July 2006; accepted 15 September 2006

Available online 15 November 2006

\begin{abstract}
The aim of this study was to evaluate the effect of ergonomic workstation design on musculoskeletal risk factors (MRFs) and musculoskeletal symptoms (MSSs) reduction among female semiconductor fabrication room (fab) worker. A prospective study was conducted to follow up 40 female fab workers over 3 months after intervention. The intervention program focused on reducing shoulder loadings for 20 female fab workers by redesigning nine workstations. Simultaneous comparisons were made for the other 20 female fab workers using original workstations. One customized observation checklist and Nordic musculoskeletal questionnaire were used to evaluate workers' MRFs and MSSs, respectively. One month after intervention, MRFs of awkward shoulder postures and repetitive motions and MSSs in shoulders for the intervention group were significantly lower than those for the control group. The lowering effects persisted for 3 months on awkward shoulder postures but lasted for only 1 month on repetitive motions and shoulder symptoms after intervention.
\end{abstract}

\section{Relevance to industry}

This study demonstrates a systematic approach for assessing effectiveness of ergonomically redesigned workstations tailored for female fab workers on reducing their awkward shoulder postures and shoulder symptoms. Industries can use our findings to design or evaluate their ergonomic intervention programs in the workplace or use our workstation specifications to purchase their manufacturing equipments in the future.

(C) 2006 Elsevier B.V. All rights reserved.

Keywords: Musculoskeletal risk factors; Musculoskeletal symptoms; Workstation; Semiconductor; VDT; Fab

\section{Introduction}

Semiconductor manufacturing (SIC code 3674) workers are potentially exposed to ergonomic hazards in the manufacturing process. Previous studies investigating work-related musculoskeletal symptoms (MSSs) in this industry have shown that semiconductor fabrication room (fab) workers have heavily involved in repetitive motion tasks of manual wafer handling and static postures of wafer inspection (Pocekay et al., 1995; Wald and Jones, 1987). Their work tasks also included frequent use of video

\footnotetext{
${ }^{*}$ Corresponding author. Tel./fax: +886223222362 .

E-mail address: ccchan@ntu.edu.tw (C.-C. Chan).

${ }^{1}$ Postal address: Room 722, No. 17, Xuzhou Rd., Taipei City 100, Taiwan, R.O.C.
}

display terminals (VDTs) for process control. It was reported that musculoskeletal problems of overexertion and repetitive motion accounted for 6.2 per 10,000 fulltime workers with nonfatal occupational injuries and 7.5 illnesses involving days away from work in the semiconductor industry in the United States in 2003 (Bureau of Labor Statistics (BLS), 2003). It was found that the prevalence of at least one body area discomfort was $55 \%$ in a study on 119 VDT users of a Taiwanese semiconductor company (Hsu and Wang, 2003).

Due to the globalization of economic activities and trades in semiconductor industries, most manufacturing equipments and automated machines used in Taiwanese companies were usually imported from other countries (MOEA, 2003). The human interface with improper anthropometric data for users in different countries might 
result in unexpected ergonomic problems, especially those of workstation-related tasks and jobs. Because the semiconductor industries usually needed to change their manufacturing process rapidly to meet the world market demands, their ergonomic hazards from inappropriate workstation designs could be more severe than other industries. Moreover, such ergonomic hazards could also affect company's productivity due to the increase of employees' sick leaves for MSSs (Aaras and Westgaard, 1987).

A prospective study showed that $10-23 \%$ nonsymptomatic computer users had more frequent MSSs in shoulder, elbow, and low back, and $14-22 \%$ had more intense symptoms after the 17-23 months follow-up (Juul-Kristensen et al., 2004). It was demonstrated that the duration of daily VDT use longer than seven hours was associated with more shoulder, neck, and low back symptoms among 1545 clerical workers (Rossignol et al., 1987). Static posture in poorly designed workstation was attributed to neck and upper extremity loadings (Sillanpaa et al., 2003).

Several intervention studies have been carried out in the past to reduce office workers' ergonomic hazards from VDT use by improving workstation designs. Computer users with wrist or forearm support were found to have fewer musculoskeletal discomforts than those with floating keying conditions (Cook et al., 2004). Aaras et al. (1998, 2001) also showed that office workers with forearm supports at VDT workstations could effectively reduce their maximum voluntary contraction (MVC) of static right trapezius muscle load from $1.5 \%$ to less than $0.3 \%$, and significantly lower their intensity of shoulder pains. By contrast, similar studies on redesigned workstation have not yet been conducted in the semiconductor manufacturing industry. Moreover, designing optimal fixed workstations for all workers in the semiconductor manufacturing fabs was a challenge because several fab workers with different heights usually shared one fixed workstation during their work. Therefore, this study was conducted to assess whether redesigning fixed workstations for optimal VDT use could effectively reduce musculoskeletal risk factors (MRFs) and MSSs among female fab workers who could not have their own adjustable workstations during the work.

\section{Materials and methods}

\subsection{Subjects}

Subjects were all recruited from bay operators in the manufacturing fab of a semiconductor company. Based on findings of a previous company survey, these workers had complains of MSSs, including shoulders (68\%), forearms $(29 \%)$, back (21\%), legs (15\%), and neck (12\%). After a walk-through observation on their working environment and discussing with company's managers in the risk management and facility departments, we found MSS in shoulders were the most prevalent and urgent ergonomic issue among their fab workers. Forty subjects were recruited to evaluate whether workstation redesign could reduce their MSSs in this study. There were 20 bay operators in the intervention group who worked in the thin film process using the redesigned workstations. There were 20 bay operators in the control group using the original workstations in the following 6 manufacturing processes: back-end etching, diffusion, front-end etching, ion implantation, photo, and thin film process. Once the subjects in the intervention group have been selected, the members in the control group were matched by their similarity of age, height, weight, employment duration, and working practice, as well as their MRFs and MSSs before intervention. A written informed consent was obtained from each participating worker before the study.

\subsection{Tasks}

Bay operators' major job functions included the following three steps: (a) using VDTs for process control at the workstations, which was normally longer than $4 \mathrm{~h}$ per shift, mostly in standing position and sometimes in sitting position; (b) lifting a $9.1 \mathrm{~kg}$ Front-Opening Unified Pod (FOUP) about 10-50 times per shift from racks to waferprocessing machines; and (c) writing production records on $\log$ books at the workstations mostly in standing and sometimes in sitting position after each manufacturing process. It took bay operators about $30-60 \mathrm{~min}$ to complete the above job functions, which were repeated by about 10-15 times in their daily work shifts. Fab workers' working hours per shift varied from the company's daily production needs. Workers were on duty for either day or night shift under a rotating two-shift system. A shift consisting of $10 \mathrm{~h}$ of work and $2 \mathrm{~h}$ of break in-between usually started at either 7:00 am or 7:00 pm. The completion of 2-day work was followed by 2 days off.

\subsection{Ergonomic intervention}

Since the ergonomic intervention program was developed to reduce shoulder symptoms, the workstations used by the intervention group were redesigned mainly to reduce workers' shoulder loadings when they were using VDTs at the workstations. The original workstation had a two-tier design with dimensions of $470 \mathrm{~mm} \times 180 \mathrm{~mm} \times 1100 \mathrm{~mm}$ for keyboard shelf and $470 \mathrm{~mm} \times 250 \mathrm{~mm} \times 900 \mathrm{~mm}$ for document and mouse shelf (Fig. 1(a)). Using keyboard of the original workstation resulted in shoulder angles greater than $40^{\circ}$ flexion and $30^{\circ}$ abduction in sitting position and shoulder angles greater than $25^{\circ}$ flexion and $30^{\circ}$ abduction in standing position among the fab workers. These body posture angles were used to determine whether workers' MRFs and MSSs would be increased by awkward shoulder postures with angles greater than $60^{\circ}$ flexion and $30^{\circ}$ abduction, which were critical angles for MRFs considered in the National Institute for Occupational Safety and Health (NIOSH) and Occupational Safety and Health 


\section{Original workstation}

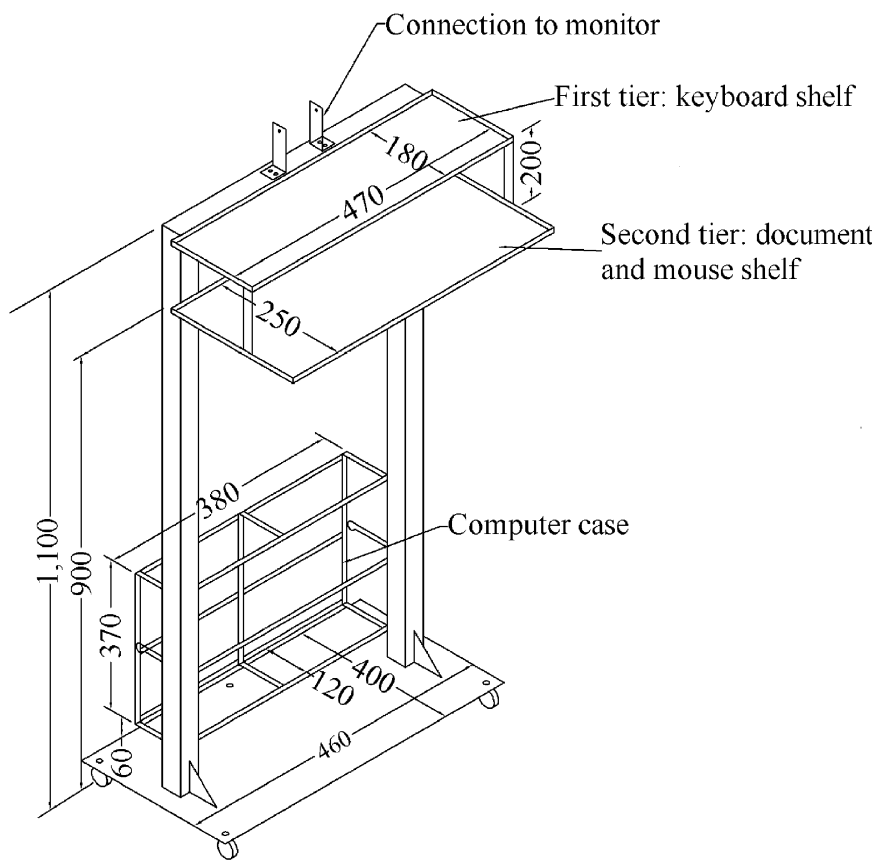

(a)

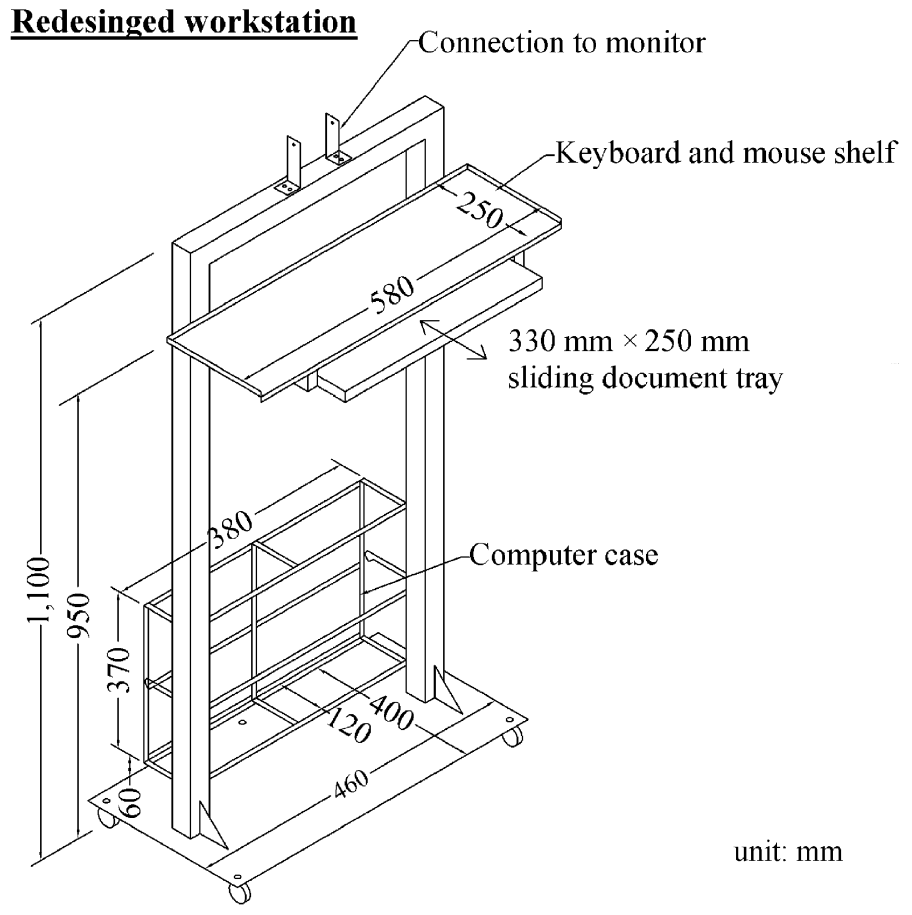

(b)

Fig. 1. The (a) original two-tier workstation with dimensions of $470 \mathrm{~mm} \times 180 \mathrm{~mm} \times 1100 \mathrm{~mm}$ for keyboard shelf and $470 \mathrm{~mm} \times 250 \mathrm{~mm} \times 900 \mathrm{~mm}$ for document and mouse shelf, and (b) redesigned workstation with dimensions of $580 \mathrm{~mm} \times 250 \mathrm{~mm} \times 950 \mathrm{~mm}$ for keyboard and mouse shelf at and $330 \mathrm{~mm} \times 250 \mathrm{~mm} \times 930 \mathrm{~mm}$ for sliding document tray.

Administration (OSHA) guideline (Bernard, 1997; Occupational Safety and Health Administration (USA) (OSHA), 2000).

Since workers often needed to take care of two to three workstations at the same time and each workstation was used simultaneously by multiple workers in the same manufacturing bay, adjustable workstations were not appropriate for them to use in the fab. Therefore, the intervention program focused on optimizing the workstation configuration to fit most workers' needs in the fab. According to the specification of workstation design by Occupational Safety and Health Administrations of the Oregon State (Oregon Occupational Safety and Health Division (OR-OSHA), 2004), the workstation's platform should be wide enough to accommodate both keyboard and mouse if the work surface was not adjustable. Another OR-OSHA specification indicated that the keyboard height should be appropriate for workers' hands being just below elbow height in order to avoid shoulder pain. Other OROSHA specifications suggested that wrists and forearms should be in a reasonably straight line and slightly above the keyboard. Lastly, workers' shoulders should be relaxed, and elbows should be next to the body. The following information was also used to redesign workstations: the study subjects' average height, the anthropometric database of 18-40 year-old Taiwanese female workers (Institute of Occupational Safety and Health (IOSH), 1997), and the OR-OSHA specification of the workstation design. On average, the height was $157.1 \mathrm{~cm}$, the height of flexed elbow at a $90^{\circ}$ angle was $97.6 \mathrm{~cm}$, and the length of wrist-to-fist was $16.8 \mathrm{~cm}$ for the 18-40 year-old Taiwanese female workers. Accordingly, the redesigned workstation's dimensions were $580 \mathrm{~mm} \times 250 \mathrm{~mm} \times 950 \mathrm{~mm}$ for keyboard and mouse shelf and $330 \mathrm{~mm} \times 250 \mathrm{~mm} \times 930 \mathrm{~mm}$ for sliding document tray installed beneath the keyboard shelf (Fig. 1(b)). Because of limited working space in the manufacturing bay, our redesigned workstations only allowed small increase in width and depth from their original dimension, but were suitable for using either in standing position or in sitting position with adjustable chairs. In comparison to the original two-tier workstation, the redesigned workstation's keyboard shelf was lowered by $150 \mathrm{~mm}$ and expanded by $110 \mathrm{~mm}$ in length and $70 \mathrm{~mm}$ in width in order to support our study subjects' forearms. Lowering keyboard's height to $950 \mathrm{~mm}$ allowed workers to keep their angles fewer than $15^{\circ}$ in standing position. The 20 fab workers in the intervention group started using these redesigned workstations in the fab for 4 months since 1 September 2004. By contrast, the fab 20 workers in the control group continued using the original two-tier workstations during the 5-month observation period.

\subsection{Data collection}

Ergonomic personal information was collected and evaluated at three evaluation periods chronologically: baseline, 1 month after intervention, and 3 months after intervention during the 5-month study. Baseline evaluation 
was performed in August 2004. After the workstation were redesigned and implemented in September 2004, two follow-up evaluations were performed in October and December 2004, respectively. In each evaluation period, one observation checklist was used to evaluate MRFs and one self-administered questionnaire was used to evaluate MSSs for each of all 40 workers. The evaluated workers first needed to fill in the questionnaire about their ages, heights, weights, employment durations in the fab, and employment durations in the company. They also provided their daily average hours spent on using VDTs, lifting FOUPs, writing documents, and doing other tasks in the fab.

One investigator filled out the customized observation checklist to evaluate workers' MRFs of awkward shoulder postures and repetitive motions by observing their working activities for 40-60 min. The observation was conducted on one worker only each time. Normally, about six such observations were completed per day. It took 1 week to complete evaluation for all 40 workers in each evaluation period. Working with repeated or sustained shoulder angles greater than $60^{\circ}$ flexion or $30^{\circ}$ abduction without forearm support totaled for longer than $4 \mathrm{~h}$ per day was considered as MRFs of awkward shoulder postures. Repeating the same motions with little or no variation every few seconds totaled for longer than $6 \mathrm{~h}$ per day, or intensive keying activities totaled for longer than $7 \mathrm{~h}$ per day was considered as highly repetitive as well as MRFs to neck, shoulders, elbows, wrists, and hands (Washington State Department of Labor and Industries, 2000). Those repetitive motions with wrist angles greater than $30^{\circ}$ flexion, $45^{\circ}$ extension, or $30^{\circ}$ ulnar deviation totaled for longer than $2 \mathrm{~h}$ per day in non-keying activities, or totaled for longer than $4 \mathrm{~h}$ per day in keying activities was also considered as highly repetitive as well as MRFs to neck, shoulders, elbows, wrists, and hands.

The evaluated workers used a self-administered questionnaire modified from the Nordic musculoskeletal questionnaire (NMQ) to report their MSSs in shoulders and back (Kuorinka et al., 1987). NMQ was chosen in this study because its validity and reliability have been confirmed by previous clinical evaluations (Deakin et al., 1994; Ohlsson et al., 1994). Workers recorded whether they had experienced MSSs of musculoskeletal ache, pain, or discomforts on their shoulders and back in the past 12 months before the baseline evaluation, and since the last evaluation in the two follow-up evaluations. Shoulder symptoms were treated as a main outcome variable and back symptoms were treated as a dummy outcome variable to falsify the findings for our intervention program in this study.

\subsection{Data analyses}

Wilcoxon signed-rank test was performed to compare mean age, height, employment duration in the fab, and employment duration in the company between the inter- vention group and the control group at baseline evaluation. Duration of different working practices over the three evaluation periods were also compared using Wilcoxon signed-rank test. For comparison between two groups, the percentages of MRFs and MSSs over the three evaluation periods were illustrated graphically and compared using the Fisher's exact test. The generalized estimating equations (GEE) models were used to estimate the effects of evaluation period on MRFs, MSSs, and duration of daily VDT use at work comparing with baseline evaluation. The odds ratios (OR) between baseline and evaluation periods were used to determine the effects of the intervention program over time. All of the analyses were computed using SAS v9.1 (SAS Institute Inc., Cary, NC).

\section{Results}

\subsection{Subjects' basic characteristics}

All of the mean age, height, weight, employment duration in the fab, employment duration in the company, and duration of working practices were not significantly different between the intervention group and the control group (Table 1). On average, their mean age, height, and weight were 26.8 year-old, $161.4 \mathrm{~cm}$, and $54.3 \mathrm{~kg}$, respectively. The mean employment duration in the fab and company was 2.1 and 4.5 years, respectively. Although the duration of working practices were not different between two groups, they varied over the three evaluation periods. Duration of daily VDT use at work was longer than $6 \mathrm{~h}$ at baseline evaluation and 3 months after intervention, but it was shorter than $5 \mathrm{~h}$ at 1 month after intervention. Lifting duration was about $2 \mathrm{~h}$ at baseline evaluation and 3 months after intervention while it was longer than $2.5 \mathrm{~h}$ at 1 month after intervention. Workers usually spent about $1 \mathrm{~h}$ on writing and other tasks.

\subsection{Comparisons between the intervention group and the control group}

Neither awkward shoulder postures $(p=1.00)$ nor repetitive motions $(p=0.34)$ had significant difference between the intervention group and the control group at baseline evaluation (Fig. 2). By contrast, there was significant difference in awkward shoulder postures between two groups at 1 month $(p=0.05)$ and 3 months $(p=0.02)$ after intervention. However, group difference in repetitive motions occurred only at 1 month after intervention $(p=0.01)$. No group difference in repetitive motions was found at 3 months after intervention $(p=0.10)$.

There was no baseline difference $(p=0.52)$ in shoulder symptoms but significant difference at 1 month after intervention $(p=0.01)$ between two groups (Fig. 3). However, no group difference in shoulder symptoms was found at 3 months after intervention $(p=0.33)$. There was 
Table 1

Comparisons of demographic characteristics and working practices between the intervention group and the control group for 40 female workers in one semiconductor fabrication room (fab) using Wilcoxon signed-rank test

\begin{tabular}{|c|c|c|c|c|}
\hline Items & Total $(n=40)$ & Intervention group $(n=20)$ & Control group $(n=20)$ & $p$ \\
\hline \multicolumn{5}{|l|}{ Demographic characteristics } \\
\hline Age in $y$, mean $(\mathrm{SD})$ & $26.8(5.1)$ & $25.7(6.0)$ & $27.9(3.9)$ & 0.12 \\
\hline Height in $\mathrm{cm}$, mean (SD) & $161.4(4.9)$ & $160.4(4.7)$ & $162.4(5.1)$ & 0.17 \\
\hline Weight in $\mathrm{kg}$, mean (SD) & $54.3(7.5)$ & $53.5(6.1)$ & $55.1(8.8)$ & 0.88 \\
\hline Employment duration in fab in y, mean (SD) & $2.1(1.0)$ & $2.0(1.3)$ & $2.1(0.7)$ & 0.74 \\
\hline Employment duration in company in y, mean (SD) & $4.5(3.8)$ & $4.0(4.2)$ & $5.0(3.5)$ & 0.14 \\
\hline \multicolumn{5}{|l|}{ Working practices in $h$} \\
\hline \multicolumn{5}{|l|}{ Video display terminal use, mean (SD) } \\
\hline Baseline & $6.2(1.6)$ & $6.3(1.8)$ & $6.2(1.5)$ & 0.98 \\
\hline One month after intervention & $4.8(1.8)$ & $4.9(1.9)$ & $4.7(1.7)$ & 0.83 \\
\hline Three months after intervention & $6.1(2.0)$ & $6.4(2.1)$ & $5.8(1.8)$ & 0.32 \\
\hline \multicolumn{5}{|l|}{ Lifting, mean (SD) } \\
\hline Baseline & $1.8(1.5)$ & $1.9(1.5)$ & $1.7(1.5)$ & 0.60 \\
\hline One month after intervention & $2.6(1.6)$ & $2.2(1.6)$ & $3.0(1.5)$ & 0.17 \\
\hline Three months after intervention & $2.0(1.4)$ & $2.0(1.3)$ & $2.1(1.5)$ & 0.94 \\
\hline \multicolumn{5}{|l|}{ Writing, mean (SD) } \\
\hline Baseline & $1.1(1.3)$ & $0.9(0.9)$ & $1.3(1.6)$ & 0.63 \\
\hline One month after intervention & $0.9(0.8)$ & $1.0(0.9)$ & $0.8(0.8)$ & 0.56 \\
\hline Three months after intervention & $0.7(1.4)$ & $0.7(1.2)$ & $0.7(1.6)$ & 0.76 \\
\hline \multicolumn{5}{|l|}{ Other tasks, mean (SD) } \\
\hline Baseline & $0.9(0.8)$ & $0.9(0.9)$ & $0.8(0.8)$ & 0.70 \\
\hline One month after intervention & $1.7(1.2)$ & $1.9(1.3)$ & $1.5(1.0)$ & 0.50 \\
\hline Three months after intervention & $1.2(1.5)$ & $0.9(1.4)$ & $1.4(1.6)$ & 0.40 \\
\hline
\end{tabular}

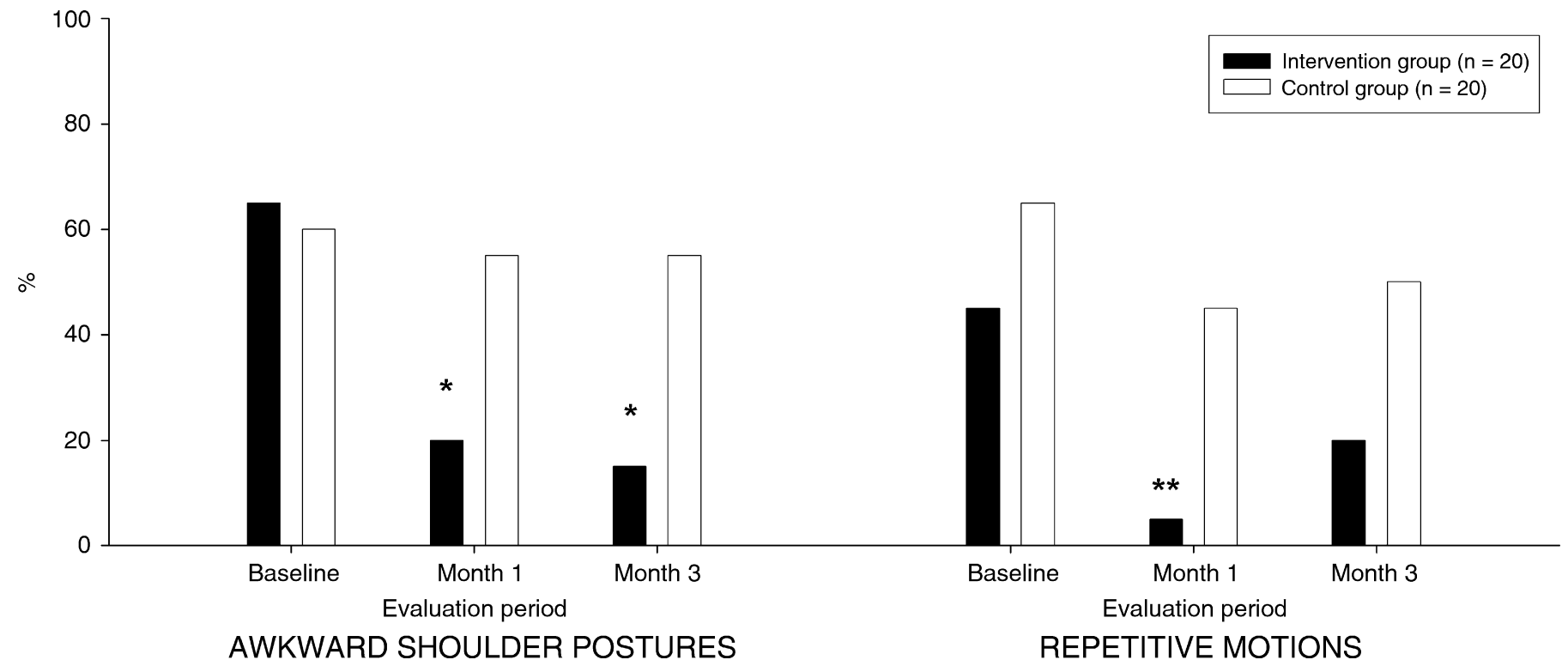

Fig. 2. Percentage of musculoskeletal risk factors (MRF), including awkward shoulder postures and repetitive motions, of the 40 female workers in one semiconductor fabrication room (fab) over the three evaluation periods. A * indicated a significant difference between the intervention group and the control group using Fisher's exact test. ${ }^{*} p<0.05,{ }^{* *} p<0.01$.

no significant difference in back symptoms between two groups over the three evaluation periods $(p>0.05)$.

\subsection{Comparisons over the three evaluation periods}

The intervention effects on reducing MRFs and MSSs were evaluated using GEE models, which compared repeated measurements of those outcomes over the three evaluation periods. The ORs of MRFs were estimated using the GEE models for both the intervention and control groups (Table 2). For the intervention group, the ORs of awkward shoulder postures at 1 and 3 months after intervention were significantly lower than that at baseline evaluation. Their respective ORs were $0.13 \quad(95 \%$ $\mathrm{CI}=0.03-0.52)$ and $0.10(95 \% \mathrm{CI}=0.02-0.53)$. By contrast, significant decrease in repetitive motions for the 


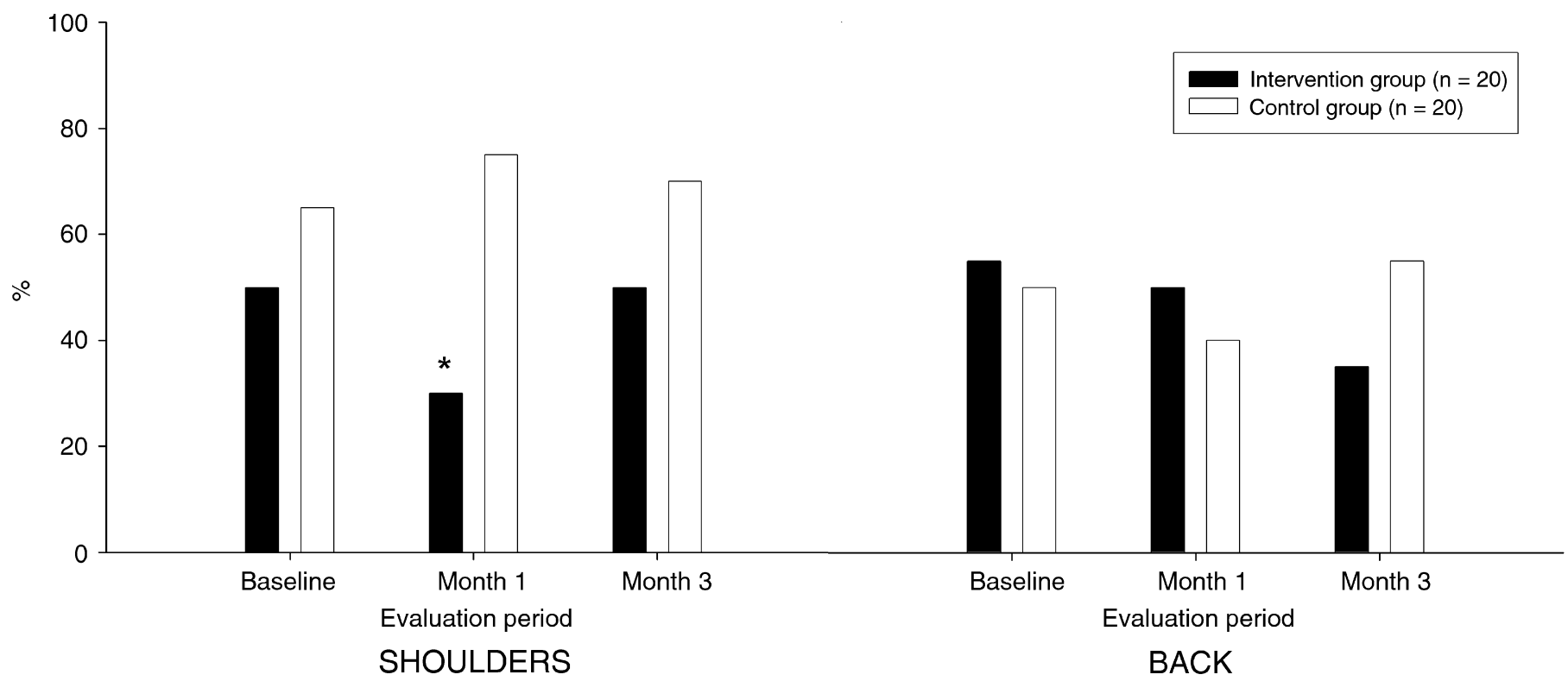

Fig. 3. Percentage of musculoskeletal symptoms (MSS) in shoulders and back of the 40 female workers in one semiconductor fabrication room (fab) over the three evaluation periods. A * indicated a significant difference between the intervention group and the control group using Fisher's exact test. * $p<0.05$.

Table 2

The effects of evaluation period after intervention on female workers' musculoskeletal risk factors (MRF), musculoskeletal symptoms (MSS), and daily video display terminal (VDT) use at work in one semiconductor fabrication room (fab) estimated using generalized estimating equations (GEE) models

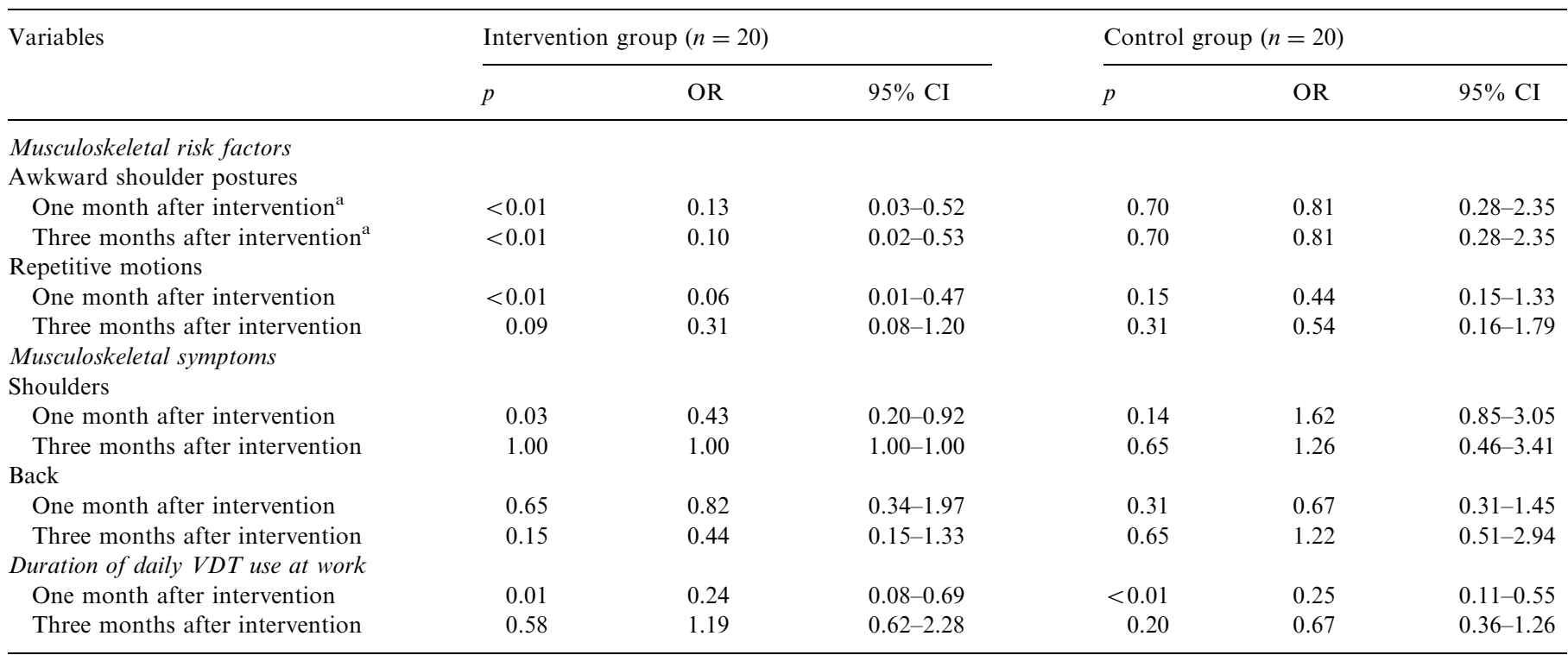

${ }^{\mathrm{a}}$ The effects of evaluation period comparing with baseline evaluation.

intervention group was only found at 1 month after intervention $(\mathrm{OR}=0.06 ; 95 \% \mathrm{CI}=0.01-0.47)$. The results showed that the evaluation period was not significantly associated with either awkward shoulder postures or repetitive motions in the control group.

The ORs of MSSs were also estimated using the GEE models for both the intervention and control groups (Table 2). Only the OR of shoulder symptoms at 1 month after intervention was significantly lower than that at baseline evaluation in the intervention group $(\mathrm{OR}=0.43$; $95 \% \mathrm{CI}=0.20-0.92)$. By contrast, the evaluation period was not significantly associated with shoulder symptoms in the control group. As to the dummy outcome of back symptoms using GEE models, the evaluation period also had no significant effect on back symptoms in either the intervention or control group.

Furthermore, the OR of duration of daily VDT use at work was estimated using the GEE models for both the intervention and control groups (Table 2). Workers' duration of daily VDT use at work at 1 month after intervention was significantly lower than that at baseline evaluation in both the intervention group $(\mathrm{OR}=0.24$; 
$95 \% \mathrm{CI}=0.08-0.69)$ and the control group $(\mathrm{OR}=0.25$; $95 \% \mathrm{CI}=0.11-0.55)$. By contrast, no significant difference in the duration of daily VDT use at work was found between baseline and 3 months after intervention in either of two groups.

\section{Discussion}

The findings in this prospective study suggested that ergonomically redesigned workstation was an effective intervention program to reduce female fab workers' awkward shoulder postures and shoulder symptoms. The intervention program was effective, because using workstation with appropriate height of keyboard shelf could reduce workers' shoulder flexion and abduction angles. By lowering the keyboard shelf's height from 1100 to $950 \mathrm{~mm}$, shoulder flexion and abduction angles became fewer than $15^{\circ}$ in both sitting and standing positions. Accordingly, workers' awkward shoulder postures were greatly reduced. In addition, the effects of forearm support had been suggested to reduce muscle loadings (Aaras et al., 1997; Bergqvist et al., 1995; Cook et al., 2004). Therefore, using keyboard with forearm support in ergonomically designed workstation should also contribute to the decrease in workers' shoulder symptoms by reducing loadings on their trapezius muscles. The fact that no intervention effect on the dummy outcome of back symptoms over the three evaluation periods indirectly supported that the intervention program actually reduced shoulder symptoms among female fab workers. This suggested that the subjective bias should be controlled.

Although female, older age, longer employment duration, high work demand, and low job control were key risk factors of musculoskeletal disorders (Bergqvist et al., 1995; Devereux et al., 2002; Skov et al., 1996), all of them should have been well controlled in this study because the demographic and anthropometric measures were similar between the intervention group and the control group. The work demand and job control were also controlled for the two groups because they had the same job titles and similar working conditions over the three evaluation periods. Moreover, the control group having no significant change in MRFs or MSSs suggested that the intervention program was effective. Therefore, the MRFs or MSSs difference between two groups in the findings could be attributed to the intervention program. However, this study was unable to quantify exposure-response relationship for ergonomic risks among fab workers mainly due to the limitation of the evaluation tools. More detailed time-activity data with exposure duration and frequency or direct measurements of electromyography (EMG) were needed in order to establish such exposure-response relationship.

The duration of daily VDT use at work is also an important factor related to workers' MSSs. In addition to ergonomic workstation designs, the duration of daily VDT use at work was one reason why the effects of intervention program could last for only 1 month after intervention in shoulder symptoms. As duration of daily VDT use at work returned to longer than $6 \mathrm{~h}$ at 3 months after intervention, shoulder symptoms was found to become insignificantly different from those at baseline evaluation. It was reported that VDT exposure time was significantly related to neck, shoulder, upper arm, finger, and back symptoms (Hsu and Wang, 2003). In terms of the duration of daily VDT use at work related to MSSs, the cut-off of $6 \mathrm{~h}$ daily in this study was comparable to 5 (Nakazawa et al., 2002) to 7 (Demure et al., 2000; Rossignol et al., 1987) hours daily in previous studies. Apparently, even though workers' awkward shoulder postures were changed by workstation redesigns, their MSSs could not be alleviated once their daily VDT use was longer than $6 \mathrm{~h}$.

This study suggested that manufacturing machines should be customized to fit the anthropometric specification of end users in order to prevent unnecessary ergonomic problems in the future. It also demonstrated a feasible customization approach to reduce workers' MRFs and MSSs by redesigning workstation to accommodate the majority of the employees. Furthermore, such a useful intervention program on reducing ergonomic hazards in the semiconductor manufacturing industries should also be a feasible ergonomic program in other industries, which shared similar difficulty in designing adjustable workstations for their workers with the semiconductor manufacturing industries. But the exact dimensions of redesigned workstations should reflect different layouts of instruments and equipments in individual industries. For companies with more diverse and heterogeneous work force than the semiconductor company in this study, we recommended to use adjustable rather fixed workstation designs to reduce ergonomic hazards for their workers.

\section{Acknowledgements}

We thank the employees and managers of the study company for their invaluable support for this study. This study could not be completed without their full cooperation in carrying out the questionnaires survey and workstation modification. We are also sincerely grateful to Dr. Jia-Hua Lin of the Liberty Mutual Research Institute for Safety in the USA for his critical comments on helping us preparing this manuscript.

\section{References}

Aaras, A., Westgaard, R.H., 1987. Further studies of postural load and musculo-skeletal injuries of workers at an electro-mechanical assembly plant. Applied Ergonomics 18 (3), 211-219.

Aaras, A., Fostervold, K.I., Ro, O., Thoresen, M., Larsen, S., 1997. Postural load during VDU work: a comparison between various work postures. Ergonomics 40 (11), 1255-1268.

Aaras, A., Horgen, G., Bjorset, H.H., Ro, O., Thoresen, M., 1998. Musculoskeletal, visual and psychosocial stress in VDU operators before and after multidisciplinary ergonomic interventions. Applied Ergonomics 29 (5), 335-354.

Aaras, A., Horgen, G., Bjorset, H.H., Ro, O., Walsoe, H., 2001. Musculoskeletal, visual and psychosocial stress in VDU operators 
before and after multidisciplinary ergonomic interventions. A 6 years prospective study — Part II. Applied Ergonomics 32 (6), 559-571.

Bergqvist, U., Wolgast, E., Nilsson, B., Voss, M., 1995. Musculoskeletal disorders among visual display terminal workers: individual, ergonomic, and work organizational factors. Ergonomics 38 (4), 763-776.

Bernard, B. (Ed.), 1997. Musculoskeletal Disorders and Workplace Factors. A Critical Review of Epidemiological Evidence for Workrelated Musculoskeletal Disorders of the Neck, Upper Extremity and Lower Back. National Institute for Occupational Safety and Health DHHS (NIOSH) Publication no. 97-141.

Bureau of Labor Statistics (BLS), 2003. Case and Demographic Characteristics for Work-related Injuries and Illnesses Involving Days Away From Work 〈http://www.bls.gov/iif/oshcdnew.htm $\rangle$.

Cook, C., Burgess-Limerick, R., Papalia, S., 2004. The effect of upper extremity support on upper extremity posture and muscle activity during keyboard use. Applied Ergonomics 35 (3), 285-292.

Deakin, J.M., Stevenson, J.M., Vail, G.R., Nelson, J.M., 1994. The use of the Nordic Questionnaire in an industrial setting: a case study. Applied Ergonomics 25 (3), 182-185.

Demure, B., Luippold, R.S., Bigelow, C., Ali, D., Mundt, K.A., Liese, B., 2000. Video display terminal workstation improvement program: I. Baseline associations between musculoskeletal discomfort and ergonomic features of workstations. Journal of Occupational and Environmental Medicine 42 (8), 783-789.

Devereux, J.J., Vlachonikolis, I.G., Buckle, P.W., 2002. Epidemiological study to investigate potential interaction between physical and psychosocial factors at work that may increase the risk of symptoms of musculoskeletal disorder of the neck and upper limb. Journal of Occupational and Environmental Medicine 59 (4), 269-277.

Hsu, W.H., Wang, M.J., 2003. Physical disorder among visual display terminal users in a semiconductor manufacturing company: a study of prevalence and relation to psychosocial and physical/ergonomic factors. American Industrial Hygiene Association Journal 64 (2), 276-282.

Institute of Occupational Safety and Health (IOSH), 1997. Static and Dynamic Anthropometric Database of Taiwanese Worker Population. IOSH86-H124 (in Chinese).

Juul-Kristensen, B., Sogaard, K., Stroyer, J., Jensen, C., 2004. Computer users' risk factors for developing shoulder, elbow and back symptoms. Scandinavian Journal of Work Environment \& Health 30 (5), 390-398.

Kuorinka, I., Jonsson, B., Kilbom, A., Vinterberg, H., Biering-Sorensen, F., Andersson, G., Jorgensen, K., 1987. Standardised Nordic questionnaires for the analysis of musculoskeletal symptoms. Applied Ergonomics 18 (3), 233-237.

Ministry of Economic Affairs (MOEA), 2003. Semiconductor Industry Yearbook. Industrial Technology Intelligence Services, Taipei, Taiwan (in Chinese).

Nakazawa, T., Okubo, Y., Suwazono, Y., Kobayashi, E., Komine, S., Kato, N., Nogawa, K., 2002. Association between duration of daily VDT use and subjective symptoms. American Journal of Industrial Medicine 42 (5), 421-426.

Occupational Safety and Health Administration (USA) (OSHA), 2000 Ergonomics Program Standard. Federal Register vol. 65, no. 220/ Tues, 14 November 2000/Rules and Regulations. 68848-68867.

Ohlsson, K., Attewell, R.G., Johnsson, B., Ahlm, A., Skerfving, S., 1994. An assessment of neck and upper extremity disorders by questionnaire and clinical examination. Ergonomics 37 (5), 891-897.

Oregon Occupational Safety and Health Division (OR-OSHA), 2004. Evaluating Your Computer Workstation. How to Make it Work for You. OR-OSHA.

Pocekay, D., McCurdy, S.A., Samuels, S.J., Hammond, S.K., Schenker, M.B., 1995. A cross-sectional study of musculoskeletal symptoms and risk factors in semiconductor workers. American Journal of Industrial Medicine 28 (6), 861-871.

Rossignol, A.M., Morse, E.P., Summers, V.M., Pagnotto, L.D., 1987. Video display terminal use and reported health symptoms among Massachusetts clerical workers. Journal of Occupational Medicine 29 (2), 112-118.

Sillanpaa, J., Nyberg, M., Laippala, P., 2003. A new table for work with a microscope, a solution to ergonomic problems. Applied Ergonomics 34 (6), 621-628.

Skov, T., Borg, V., Orhede, E., 1996. Psychosocial and physical risk factors for musculoskeletal disorders of the neck, shoulders, and lower back in salespeople. Journal of Occupational and Environmental Medicine 53 (5), 351-356.

Wald, P.H., Jones, J.R., 1987. Semiconductor manufacturing: an introduction to processes and hazards. American Journal of Industrial Medicine 11 (2), 203-221.

Washington State Department of Labor and Industries, 2000. Ergonomics Rule, (WAC) WAC296-62-051, Ergonomics 〈http://www.Ini.wa. gov/WISHA/Rules/GeneralOccupationalHealth/PDFs/ErgoRulewith Appendices.pdf $\rangle$. 